\title{
Research Article \\ Clinicopathological profile of invasive ductal breast carcinoma in a government tertiary care center in eastern India
}

\author{
Mrityunjay Pal ${ }^{1}$, Saugata Ray ${ }^{2}$, Priyanka Rani ${ }^{3}$, Gautam Prakash ${ }^{4}$, Raju Gupta ${ }^{5}$ \\ ${ }^{1}$ Assistant Professor, ${ }^{2}$ Associate Professor, ${ }^{4}$ Postgraduate student, Department of General Surgery, Midnapore Medical \\ College, West Midnapore, 721 101, West Bengal, India \\ ${ }^{3}$ Postgraduate student, Department of Obstetrics and Gynecology, Vardhaman Mahavir Medical College, New Delhi, 110 \\ 029 India \\ ${ }^{5}$ School of Medical Science and Technology, Indian Institute of Technology, Kharagpur, West Midnapore, 721 302, West Ben-
} gal, India

(Received: August $2020 \quad$ Revised: October 2020

Accepted: December 2020)

Corresponding author: Gautam Prakash. Email: gautamprakash27@gmail.com

\begin{abstract}
Introduction and Aim: There is an increasing incidence of breast cancer (BC) in our country. The study aimed to find out the demographic profile, clinical presentation, and management in patients treated for invasive ductal breast carcinoma (IDC) in a rural government teaching hospital and to study the association of sociodemographic factors with BC stage.

Materials and Methods: The study retrospectively analyzed 100 IDC females treated at Midnapore medical college, West Bengal, India from January 2017 to December 2019. The study included female patients of all ages diagnosed with IDC who had undergone surgery. Male BC, bilateral BC, other pathological types of BC were excluded.

Results: The mean age was $56.54 \pm 12.99$ years. Sixty-seven cases were postmenopausal. Eighty-one cases were from rural areas. Seventy-three cases had education up to middle school. Eighty-six cases had a lower socioeconomic status. Ninety-eight cases had unilateral breast lump and only $2 \%$ had a nonpalpable breast lump. The left breast was more commonly involved. The mean tumour size was $4.33 \mathrm{~cm}$. Ninety-eight cases underwent a modified radical mastectomy. Stage III was the most commonly observed BC and seen in 40 cases followed by stage II in 36 cases. Sixty-one cases had advanced BC. Liver metastasis was seen in 21cases. Sixty-nine cases had axillary node(ALN) positivity. Sixty-eight cases had lymphovascular emboli (LVE). High-grade tumour was seen in $77 \%$. High-grade tumour was more common in young women. Seventy three cases of tumours were estrogen receptor-positive $(\mathrm{ER}+)$ while $66 \%$ progesterone receptor-positive $(\mathrm{PR}+)$. Eighteen cases were human epidermal growth factor 2 receptor-positive.
\end{abstract}

Conclusion: High incidence of advanced BC is found in rural areas due to a lack of awareness and health infrastructure.

Keywords: Ductal breast carcinoma; ALN; LVE; mastectomy; estrogen receptors; progesterone receptors

\section{INTRODUCTION}

$\mathrm{V}$ aried clinicopathological features of breast cancer (BC) have been reported across India reflecting the urban-rural divide and varying socioeconomic status. BC incidence and mortality are rapidly growing worldwide. $\mathrm{BC}$ is a leading cause of cancer-related death among women worldwide. There are around 2.1 million new cases of $\mathrm{BC}$ in the year 2018 along with 0.62 million deaths. In India, 1.6 lakh newly diagnosed cases of $\mathrm{BC}$ with 0.87 lakh deaths were reported (1). The reasons for increase in newly diagnosed cases of $\mathrm{BC}$ are mainly due to aging population, improved cancer care facilities, easy availabilities of low-cost BC screening facilities. BC can be treated completely if detected in an early stage and requires a multimodality approach involving radiotherapy, chemotherapy, hormonal therapy for hormonesensitive tumors along with mastectomy (2). Late- stage $\mathrm{BC}$ is associated with low socioeconomic development, illiteracy, lack of BC awareness, lack of BC screening facilities, and lack of multidisciplinary treatment set up in rural areas (2). The purpose of our study was to describe the clinicopathological profile of BC in rural areas and to study the association of sociodemographic factors with the $\mathrm{BC}$ stage at diagnosis.

\section{MATERIALS AND METHODS}

This retrospective study was done on patients treated over three years at Midnapore medical college and hospital, West Midnapore, West Bengal, India, from January 2017 to December 2019 with the diagnosis of invasive ductal carcinoma (IDC) in our hospital. Institute ethical committee permission was taken before study. Inclusion criteria were female patients of all ages diagnosed as IDC who had undergone surgery. Exclusion criteria included pregnant females with BC, male $\mathrm{BC}$, bilateral BC, other pathological types of BC, and patients who did not undergo surgery for $\mathrm{BC}$. 
Procedure: Clinicopathological diagnosis of IDC was made with detailed history, physical examination findings, metastatic workup by doing ultrasonography, chest, skull, and spine radiographs, computed tomography scan, and confirmed by tissue biopsy with histopathology and immunohistochemistry. Final TNM staging was done based on the American Joint Committee on Cancer (AJCC) 8th edition after clinico-histopathological reports. All patients of IDC were selected for a surgical management. All patients underwent preoperative anesthetic fitness followed by surgical intervention. The choice of surgery was mainly modified radical mastectomy and toilet mastectomy. Two drains were placed, one in the subcutaneous layer and the other in the axilla. Patients received chemotherapy in the radiotherapy department but were referred to a higher center for radiation therapy as it is not available at our center.

\section{Data collection and statistical analysis}

Data of these patients were collected and assessed from medical records department and recorded for epidemiology, demographic profile, clinical presenta- tion, and surgical management, the operative procedure is done, postoperative care and clinical outcomes in terms of length of hospital stay (LOHS), morbidity, mortality, histopathological and immunotherapy reports. Statistical calculations were carried out using the Statistical Package for the Social Sciences software version 26.0 (SPSS-26.0, IBM, Chicago, USA). The numerical tool for the study variables applied was the Independent Sample Student t-test. The mean \pm standard deviation, median, confidence interval (CI), mean difference (MD), degree of freedom(df), and Pvalue $(\mathrm{P})$ were calculated. The non-parametric test was applied for categorical data. The statistical significance of associations between the various qualitative parameters was evaluated through the Chi-square test/Fisher's exact test (two-tail). Differences were considered significant when $\mathrm{P}<0.05$.

\section{RESULTS}

The study population constituted of 100 female IDC patients. The youngest patient was 27 years and the oldest was 82 years old. Table 1 shows the demographic profile of the study population.

Table 1: Demographic profile

\begin{tabular}{|c|c|c|c|c|c|}
\hline S. No. & Variables & Total & ALN negative & ALN positive & $\mathbf{P}$ \\
\hline I & Mean Age \pm SD & $56.54 \pm 12.99$ & $54.61 \pm 14.74$ & $57.41 \pm 12.14$ & 0.360 \\
\hline II & \multicolumn{4}{|c|}{ Marital status } & 0.78 \\
\hline & Unmarried & 4 & 1 & 3 & \\
\hline & Married & 80 & 26 & 54 & \\
\hline & Widowed & 14 & 4 & 10 & \\
\hline & Divorced & 2 & 0 & 2 & \\
\hline III & \multicolumn{4}{|c|}{ Menstrual status } & 0.416 \\
\hline & Premenopausal & 33 & 12 & 21 & \\
\hline & Postmenopausal & 67 & 19 & 48 & \\
\hline IV & \multicolumn{4}{|c|}{ Place of residence } & 0.023 \\
\hline & Rural & 81 & 21 & 60 & \\
\hline & Urban & 19 & 10 & 9 & \\
\hline $\mathbf{V}$ & \multicolumn{4}{|c|}{ Level of schooling } & 0.024 \\
\hline & $\begin{array}{l}\text { Up to middle } \\
\text { school }\end{array}$ & 73 & 18 & 55 & \\
\hline & $\begin{array}{l}\text { Above middle } \\
\text { school }\end{array}$ & 27 & 13 & 14 & \\
\hline VI & \multicolumn{4}{|c|}{ Socioeconomic status } & 0.404 \\
\hline & Lower & 86 & 28 & 58 & \\
\hline & Middle & 14 & 3 & 11 & \\
\hline
\end{tabular}

The maximum age incidence was seen in the 45-54 years $(26 \%)$. Only $7 \%$ were below the age of 35 years. Nearly $11 \%$ of cases were below 40 years while $30 \%$ of cases were above the age of 65 years. The overall mean age was $56.54 \pm 12.99$ years $(\mathrm{CI}=53.96-59.12)$. The mean age of cases with lymph node positivity was found to be $57.41 \pm 12.14$ years as compared to $54.61 \pm 14.74$ years in negative cases. $80 \%$ of females were married while only 4 females were unmarried. $67 \%$ were postmenopausal and $33 \%$ were premenopausal women. About $81 \%$ of patients were from rural areas while $73 \%$ of patients had schooling below the Table 2: Clinico-surgical patient profile middle level (class VIII). $86 \%$ of patients belonged to low socioeconomic status.

The incidence of $\mathrm{BC}$ was more commonly seen on the left breast (52\%). Table 2 shows the clinico-surgical profile of the study population. Unilateral breast lump was found in 98 cases (98\%) followed by axillary swelling in 20 cases $(20 \%)$. Only $2 \%$ of patients had presented as axillary swelling only without any palpable breast lump. Ulcerative breast mass was found in 9 cases $(9 \%)$. 


\begin{tabular}{|c|c|c|c|c|c|}
\hline S. No. & Variables & Total & ALN negative & ALN positive & $\mathbf{P}$ \\
\hline I & \multicolumn{4}{|c|}{ Side } & 0.703 \\
\hline & Right & 48 & 14 & 34 & \\
\hline & Left & 52 & 17 & 35 & \\
\hline II & \multicolumn{4}{|c|}{ Presentation } & 0.013 \\
\hline & Lump & 80 & 28 & 52 & \\
\hline & $\begin{array}{c}\text { Axillary swelling } \\
\text { only }\end{array}$ & 2 & 2 & 0 & \\
\hline & $\begin{array}{l}\text { Lump + Axillary } \\
\text { swelling }\end{array}$ & 9 & 1 & 8 & \\
\hline & $\begin{array}{c}\text { Lump + Axillary } \\
\text { swelling + Skin } \\
\text { changes }\end{array}$ & 9 & 0 & 9 & \\
\hline III & \multicolumn{4}{|c|}{ Surgery } & 0.338 \\
\hline & MRM & 98 & 31 & 67 & \\
\hline & TOM & 2 & 0 & 2 & \\
\hline IV & \multicolumn{4}{|c|}{ Complication } & 0.314 \\
\hline & MGS & 7 & 1 & 6 & \\
\hline & Absent & 88 & 30 & 58 & \\
\hline & Seroma & 2 & 0 & 2 & \\
\hline & Wound infection & 3 & 0 & 3 & \\
\hline
\end{tabular}

*ALN=Axillary lymph node, MRM= Modified radical mastectomy, TOM= Toilet mastectomy, MGS= Marginal gangrenous skin flap

The median time lag between diagnosis and mastectomy was 23 days. Modified radical mastectomy was done in 98 cases (98\%) while toilet mastectomy was done in 2 cases of ulcerative mass. Most of the patients $(88 \%)$ did not develop any complication in the postoperative period. The most common post-surgical complication observed was marginal gangrenous skin flap $(7 \%)$, wound infection (3\%), and seroma formation (2\%) as shown in table 2 . All patients were discharged successfully, and no death was recorded during the post operative period. The mean length of hospital stay post-mastectomy was $7.06 \pm 1.51$ days.

The stage III BC was the most commonly observed stage of presentation with 40 cases $(40 \%)$ followed in decreasing order of frequency by stages II with 36 cases (36\%), IV with 21 (21\%) cases, and stage I with only 3 cases (3\%). Table 3 shows the tumor staging of the study population.

Table 3: Tumour staging

\begin{tabular}{|c|c|c|c|c|c|}
\hline S. No. & Variables & Total & ALN negative & ALN positive & $\mathbf{P}$ \\
\hline I & Size \pm SD $(\mathrm{cm})$ & $4.33 \pm 1.51$ & $4.11 \pm 1.40$ & $4.43 \pm 1.56$ & 0.310 \\
\hline II & \multicolumn{4}{|c|}{ T stage } & 0.201 \\
\hline & $\mathrm{T} 1$ & 10 & 3 & 7 & \\
\hline & $\mathrm{T} 2$ & 68 & 24 & 44 & \\
\hline & T3 & 13 & 4 & 9 & \\
\hline & $\mathrm{T} 4$ & 9 & 0 & 9 & \\
\hline III & \multicolumn{4}{|c|}{$\mathrm{N}$ stage } & 0.000 \\
\hline & N0 & 28 & 26 & 2 & \\
\hline & N1 & 35 & 2 & 33 & \\
\hline & $\mathrm{N} 2$ & 22 & 3 & 19 & \\
\hline & N3 & 15 & 0 & 15 & \\
\hline IV & \multicolumn{4}{|c|}{ M stage } & 0.017 \\
\hline & Absent & 79 & 20 & 59 & \\
\hline & Present & 21 & 11 & 10 & \\
\hline $\mathbf{V}$ & \multicolumn{4}{|c|}{ Tumour stage } & 0.00002 \\
\hline & Stage I & 3 & 0 & 3 & \\
\hline & Stage II & 36 & 18 & 18 & \\
\hline & Stage III & 40 & 2 & 38 & \\
\hline & Stage IV & 21 & 11 & 10 & \\
\hline
\end{tabular}

$* \mathrm{SD}=$ Standard deviation, ALN=Axillary lymph node

Of the 21 metastatic cases, 21 had hepatic and 4 cases had both hepatic and lung. One case was found to have skull metastasis. The mean age at presentation showed an increasing trend from stage IV to stage I. The mean was found to be 57.00 years for cases in stage III as compared to 53.33 years for cases in stage IV and was found to be statistically significant $(\mathrm{P}=0.00002)$. Sixty-nine percent of patients had tumour size between $>2-5 \mathrm{~cm}$. The mean tumour size was $4.33 \pm 1.51$ $\mathrm{cm}(\mathrm{CI}=4.05-4.66)$. The mean tumour size showed an increasing trend form stage I to stage IV. The mean 
tumour size was for stages I, II, III, and IV was $2 \mathrm{~cm}$, $3.91 \mathrm{~cm}, 4.65 \mathrm{~cm}$, and $4.75 \mathrm{~cm}$ respectively.

Histopathological confirmation of axillary lymph node positivity (ALN +ve) was observed in 69 cases (69\%). Table 4 had shown the histopathological and immunochemistry profile of the study population. The mean tumour size of cases with lymph node positivity was found to be $4.43 \pm 1.56 \mathrm{~cm}$ as compared to $4.11 \pm 1.4 \mathrm{~cm}$ in negative cases. About $68 \%$ of cases were found to be associated with lymphovascular emboli. The differences were found to be statistically significant. The mean age of cases with lymphovascular emboli was found to be $53.22 \pm 14.1$ years as compared to $58.10 \pm 12.2$ years in negative cases. The mean tumour size of cases with lymphovascular invasion was found to be $4.38 \pm 1.5 \mathrm{~cm}$ as compared to $4.31 \pm 1.5 \mathrm{~cm}$ in negative cases and was statically significant. About $69 \%$ patients had high grade $(3+)$ tumour. The mean age of cases with Grade 1, 2, and 3 tumour was found to be $65.00 \pm 15.55$ years, $57.62 \pm 12.28$ years, and $55.84 \pm 13.30$ years respectively. Immunohistochemistry had reported Estrogen Receptor (ER+), Progesterone Receptor $(\mathrm{PR}+)$, and Human epidermal growth factor receptor (Her-2-neu 3+) rates in 73\%, 66\% and $18 \%$ respectively. The differences were found to be statistically significant for both $\operatorname{ER}(\mathrm{P}=0.03)$ and $\mathrm{PR}(\mathrm{P}=0.001)$. Both $\mathrm{ER}$ and $\mathrm{PR}$ positive tumors were seen in $74 \%$ of cases. The mean age of cases with $\mathrm{ER}+, \mathrm{PR}+$, Her-2-neu 3+ tumours was found to be $57.29 \pm 12.88$ years, $57.89 \pm 12.25$ years, and 60.28 \pm 12.2 years respectively.

Table 4: Histopathological and immunochemistry profile

\begin{tabular}{|c|c|c|c|c|c|}
\hline S. No. & Variables & Total & ALN negative & ALN positive & $\mathbf{P}$ \\
\hline I & \multicolumn{4}{|c|}{ Tumour margin post mastectomy } & 0.663 \\
\hline & Negative & 94 & 30 & 64 & \\
\hline & Positive & 6 & 1 & 5 & \\
\hline II & \multicolumn{4}{|c|}{ Lymphovascular emboli } & 0.000 \\
\hline & Absent & 32 & 20 & 12 & \\
\hline & Present & 68 & 11 & 57 & \\
\hline \multirow[t]{4}{*}{ III } & \multicolumn{4}{|c|}{ Grade } & 0.086 \\
\hline & 1 & 2 & 0 & 2 & \\
\hline & 2 & 29 & 5 & 24 & \\
\hline & 3 & 69 & 26 & 43 & \\
\hline \multirow[t]{3}{*}{ IV } & \multicolumn{4}{|c|}{ Estrogen receptor (ER) } & 0.030 \\
\hline & Negative & 27 & 13 & 14 & \\
\hline & Positive & 73 & 18 & 55 & \\
\hline \multirow[t]{3}{*}{$\mathbf{V}$} & \multicolumn{4}{|c|}{ Progesterone receptor (PR) } & 0.001 \\
\hline & Negative & 34 & 18 & 16 & \\
\hline & Positive & 66 & 13 & 53 & \\
\hline VI & \multicolumn{4}{|c|}{ Human epidermal growth factor 2 receptor (HER2) } & 0.228 \\
\hline & 0 & 41 & 16 & 25 & \\
\hline & 1 & 17 & 3 & 14 & \\
\hline & 2 & 24 & 5 & 19 & \\
\hline & 3 & 18 & 7 & 11 & \\
\hline
\end{tabular}

\section{DISCUSSION}

The present research focuses on the estimation of IDC patients treated in a peripheral teaching hospital of the West Midnapore district, West Bengal, India. Age is an important risk factor and the incidence of BC risk increases as age advances, as is well documented in the literature (1-10). The commonest age group of BC incidence was $45-54$ years (26\%) and a similar finding has been observed in other studies (3). The mean age at presentation showed an increasing trend for the various stages and a similar finding has been observed in other studies (3). The mean age was 56.54 years which was similar to other studies $(4,5)$. In our study, $67 \%$ of the cases were postmenopausal women which is in agreement with the other studies (3-7). A majority of the patients were found to be of rural areas and a similar finding has been observed in other studies $(4,8)$. In our study, we found that those with lower than middle school education level had presented with advanced BC. A significant association was seen in our study between BC and educational level. A low level of education and lack of health infrastructure lead to low rate of breast cancer screening in rural areas. This emphasizes the need for breast cancer awareness programs to be better implemented in rural areas.

Lump in the breast was the chief presenting complaint in a majority of the patients, similar observation had been reported in other studies $(3,4,6,8)$. The left breast was more affected and is similar to other studies $(4,8)$. The most common site of metastasis was the liver and a similar finding has been observed in other studies $(3,8)$. A significant finding in our study is that $61 \%$ of the cases were advanced stage BC due to lack of cancer health services in rural areas and is similar to the other Indian and Asian studies where large and advanced tumours are common findings $(3,4,6,7,8)$. 
Multiple factors lead to advanced $\mathrm{BC}$ in Indian women, lack of access to health facilities, and limited availability and access to cancer health services. The majority of the patients underwent MRM and a similar finding has been observed in other studies $(3,4,7,8)$. The high rate of MRM is mainly due to unacceptability of safety in conservative surgery, lack of radiotherapy unit in our institution, affordability of treatment, lack of regular follow up visits, and other compliance issues. The lymph node positivity rate, presence of lympho-vascular emboli, high-grade tumour, and hormonal receptor status findings in our study are consistent with other studies $(4,5,7,9,10)$. The high-grade tumour was found to be more associated with a younger age group while ER+ and PR+ tumour was more commonly associated with older age women $(4,5,7,9,10)$.

\section{CONCLUSION}

Breast cancer is a major disease burden in our country. With better clinical and diagnostic modalities, breast cancer in the early stage (stage I and II) is better treated with low morbidity and mortality and the economic burden is also low. But due to lack of education, low socioeconomic conditions and lack of awareness about BC in rural areas patients usually present in an advanced stage. Young age, advanced disease, highgrade tumour, triple-negative breast cancer was associated with poor prognosis and difficult to treat. So, emphasis should be put more on early detection of BC, and better availability of treatment at rural tertiary care centers. The study lacks follow up recordings of patients. So, long term complication and long-term clinical outcome of care could not be defined.

\section{CONFLICT OF INTEREST}

Authors declare no conflict of interest.

\section{REFERENCES}

1. Bray, F., Ferlay, J., Soerjomataram, I., Siegel, R. L., Torre, L.A., Jemal, A. Global cancer statistics 2018: GLOBOCAN estimates of incidence and mortality worldwide for 36 cancers in 185 countries. CA: A cancer journal for clinicians. 2018; 68(6): 394-424. https://doi.org/10.3322/caac.21492

2. Townsend, C. M., Beauchamp, R. D., Evers, B. M., editors. Sabiston Textbook of Surgery. First South Asia edition. India: Elsevier; 2016.

3. Saxena, S., Rekhi, B., Bansal, A., Bagga, A., Chintamani, Murthy, N.S. Clinico-morphological patterns of breast cancer including family history in a New Delhi hospital, India-a cross-sectional study. World journal of surgical oncology 2005; 3: 67. https://doi.org/10.1186/1477-7819-3-67

4. Nene, B. M., Selmouni, F., Lokhande, M., Hingmire, S. J., Muwonge, R., Jayant, K., et al., Patterns of Care of Breast Cancer Patients in a Rural Cancer Center in Western India. Indian Journal of Surgical Oncology. 2018; 9(3):374380. https://doi.org/10.1007/s13193-018-0748-4

5. Gadgil, A., Roy, N., Sankaranarayanan, R., Muwonge, R., Sauvaget, C. Effect of comprehensive breast care on breast cancer outcomes: a community hospital-based study from Mumbai, India. Asian Pacific Journal of Cancer Prevention. 2012; 13(4): https://doi.org/10.7314/apjcp.2012.13.4.1105
6. Ali, R., Mathew, A., Rajan, B. Effects of socio-economic and demographic factors in delayed reporting and late-stage presentation among patients with breast cancer in a major cancer hospital in South India. Asian Pacific Journal of Cancer Prevention. 2008; 9(4): 703-707.

7. Nair, N., Shet, T., Parmar, V., Havaldar, R., Gupta, S., Budrukkar, A., et al., Breast cancer in a tertiary cancer center in India - An audit, with outcome analysis. Indian Journal of Cancer. 2018; 55(1): 16-22. https://doi.org/10.4103/ijc.IJC_484_17

8. Sandhu, D. S., Sandhu, S., Karwasra, R. K., Marwah, S. Profile of breast cancer patients at a tertiary care hospital in north India. Indian Journal of Cancer. 2010; 47(1): 16-22. https://doi.org/10.4103/0019-509X.58853

9. Kakarala, M., Rozek, L., Cote, M., Liyanage, S., Brenner, D.E. Breast cancer histology and receptor status characterization in Asian Indian and Pakistani women in the U.S.--a SEER analysis. BMC Cancer. 2010; 10: 191. https://doi.org/10.1186/1471-2407-10-191

10. Anderson, W. F., Chatterjee, N., Ershler, W. B., Brawley, O.W. Estrogen receptor breast cancer phenotypes in the Surveillance, Epidemiology, and End Results database. Breast Cancer Research and Treatment. 2002; 76(1): 27-36. https://doi.org/10.1023/a:1020299707510 